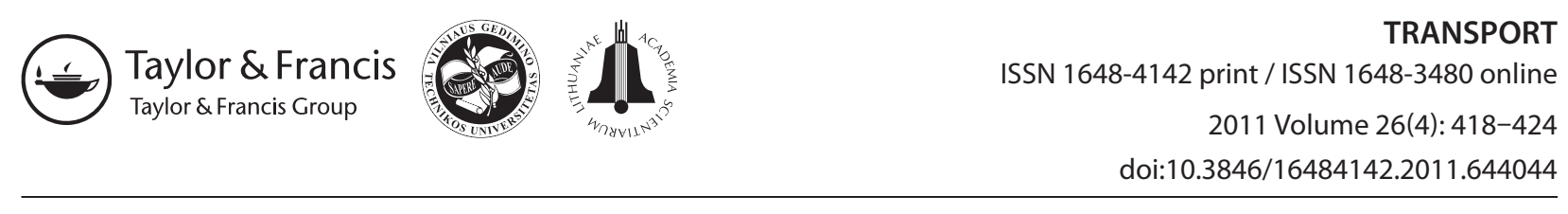

\title{
TARGET MODAL SPLIT MODEL
}

\author{
Valentina Basarić ${ }^{1}$, Jadranka Jović ${ }^{2}$ \\ ${ }^{1}$ Faculty of Technical Sciences, University of Novi Sad, Trg Dositeja Obradovića 6, \\ 21000 Novi Sad, Serbia \\ ${ }^{2}$ Transport and Traffic Engineering Faculty, University of Belgrade, Vojvode Stepe 305, \\ 11000 Belgrade, Serbia \\ E-mails: ${ }^{1}$ plast@uns.ac.rs; ${ }^{2}$ j.jovic@sf.bg.ac.rs (corresponding author)
}

Submitted 11 March 2011; accepted 11 May 2011

\begin{abstract}
The research presented in this paper is aimed at defining a model that enables the management of the relationship between private vehicles and public transport applying the available instruments of city transport policy such as parking policy and public transport policy measures. Statistical data used for modelling is sourced from the database in a wide range of EU cities. The target model was developed in the form of stepwise regression analysis. Very favourable statistical results were obtained, and the subsequent tests on the city of Novi Sad (250000 inhabitants) led to the conclusion that the obtained results were suitable for implementation in practice. The results of the implemented procedure are of great importance for the enhancement of the existing transport policies in cities, as they enable the development of strategies for finding combinations of instruments that would bring the transport system and urban environment into a desired-viable rather than consequential condition.
\end{abstract}

Keywords: modal split, sustainable transport, traffic demand management, parking policy, regression analysis.

\section{Introduction}

Traffic models are important tools for traffic forecasting and transportation system management in cities. The experience of using four-step models for defining future traffic demand over several decades has been subject to criticism mainly based on the fact that conventional models only extrapolate the present situation into the future, i.e. do not provide instruments for traffic demand management.

In transportation planning, modal split represents a method used for determining either the potential number of trips by mode or the share of different modes of transport and pedestrian trips in the total transport needs. Modal split forms an integral part of the transport development strategy of any surveyed district (Ortúzar, Willumsen 2001). A number of different approaches to currently used modal split are based on the aims, scope and nature of research, the availability of basic information, etc. The identification of the factors that influence modal split provides basis for modal split modelling. However, it is difficult to quantify many potential factors and make a reliable forecast. The major problem is research into the factors of a split between public and personal transport.
Modal split models used for simulating the selected mode are mostly based on official statistics (the number of inhabitants in the district, motorization degree, income, etc.) and may include data provided by transport studies (travel time or distance) (Jovanović 1990). The relevance of these parameters in analysis and modelling the selected mode depends on input availability and quality. Data on relevant parameters is obtained from census records and some systemic local statistics that are made periodically, mostly not for transport studies. Most models rely on the linear relationship between the variables on assumption that their effect is continuous, thus neglecting any stress such as the imposition of restrictions on fuel consumption, an abrupt decline of living standards, etc. Due to their simplified form, the models fail to fully capture mutual influences. The problem concerning aggregate four-step models involves a lack of feedback between different steps. A change in transport conditions can modify not only the selected mode but also trip generation, time and spatial split. In some models, an effort to model simultaneous decision-making by individuals (e.g. a simultaneous selection of the mode and destination) was made. These models are more realistic. However, they did not always pay attention to all possible interactions, and may exclude changes in the 
travel schedule of an individual or linked trips. The organization of a trip within a group (e.g. household) has a significant effect on the users' behaviour, and therefore makes difficulties to include this in the model. The complexity of changes, especially with respect to the trips that are not work-related, is not adequately simulated or explained by the available models. Many factors play a decisive role and can be imperfectly presented by traditional variables. The analyzed relationships are limited to the value range often neglected in further analysis. Individual or group behaviour is very flexible. According to previous experience in transportation planning, significant deviations were observed in the users' behaviour with respect to socio-economic and engineering rules. Thus, for example, the models are based only on time (distance, speed) spent directly on travel rather than on time spent on travel itself (users' opinion) etc. The survey of various modal split methods identified three most widely used model groups:

- methods applied for setting planners' aims and making modal split assuming that the users will be influenced as desired, but without a clear recognition of real users' behavior;

- analytical methods are employed on the basis of available data, thus developing a modal split model, including relevant parameters that are evaluated using engineering methods in real terms (time - travel time, distance, etc.) during forecasting;

- methods that partially rely on real users' behaviour, including inertness (habits), with respect to changes in the mode, inadequate information level, subjective evaluation and hostility towards a change, standing during the ride, etc.

By applying a normative modal split model, it is not possible to determine the real user's behaviour and patterns of using the future transport system. The second group of methods found widespread use. It belongs to standard engineering methods but its range of parameters is modest. The third group is still being developed and is hesitantly coming into use as a corrective part of the planners' methods. Consequently, it is used for improving the performance of the models in the second group. The application of these methods is still inadequate, since their theoretical basis has not yet been developed so as to guarantee a successful application of new modal split models, including the users' real response or behaviour with respect to transport alternatives (Jović 1997).

Traffic demand management (TDM) is a relatively new method of defining the relationships within traffic demand employing the strategy that reduces the use of private cars and redistributes traffic load to more energy efficient and eco-friendly (EFMT) modes of transport, primarily favouring public transport, bicycle and pedestrian traffic (Jović et al. 2008; Litman 2011).

The main issue related to four-step modelling in transportation planning is the exclusion of the effect of supply on the total volume, travel distribution and choosing the means of transport. The parameters of supply for the transportation system have a retroactive impact on the potential customer's decision whether to travel or not, which mode of transport to use and a location to choose in order to realize travel motives. These parameters are typically affected by the transport network and its characteristics, and this way, appear in the four-step model as input data for traffic assignment.

This paper explains the procedure of target modal split modelling (Basarić 2010) that identifies and includes the characteristics of the transportation system in modelling transportation demand.

\section{Methodology}

The initial development stage of the mathematical form of the modal split model comprised a collection of a wide range of socio-economic data, characteristics of supply to the extant transport system and the percentage participation of different modes of transport in modal split. Data was collated from approximately 150 European cities with the population ranging from 50000 to 1500000 inhabitants (European Urban Statistics... 2009).

The characteristics of supply for the socio-economic and extant transportation system are defined as independent variables, i.e. model inputs (Table 1).

The probabilities of using individual means of transportation (public transport, passenger car, bicycle, motorcycle and walking) in modal split are taken as potential dependent variables in the model. They are derived by transforming the individual means of transportation shares in the modal split of the analyzed city transportation systems.

As an additional variable, the public transport to passenger car probability ratio was tested as a potential variant of the dependent variable in the mathematical model (Table 2).

Variable correlations that enabled the identification of cities and variables significant for forming the mathematical modal split model were analyzed.

A general form of the multiple linear regression model was assumed:

$$
y=\alpha_{0}+\beta_{1} x_{1}+\beta_{2} x_{2}+\ldots+\beta_{p} x_{p}+\varepsilon^{\prime},
$$

where: $y$ is the dependent variable value defined as the probability of using individual modes of transport or public transport to passenger car probability ratio; $x_{1}, \ldots, x_{n}$ are independent (explanatory) variable values.

Random error $\varepsilon^{\prime}$ represents the stochastic part of the model and is introduced by the factors not included in the model. It is assumed that $\varepsilon_{i}$ are uniformly distributed independent values with $N\left(\mu, \sigma^{2}\right)$. Elements $\alpha_{0}$, $\beta_{1}, \ldots, \beta_{p}$ are unknown regression parameters representing the effect of individual variables on the dependent variable. In order to obtain a relative effect of individual independent variables on the dependent variable, $t$-test values, partial correlations and beta coefficients were calculated according to:

$$
\beta_{i}^{*}=\beta_{i} \cdot \frac{S_{x_{i}}}{S_{y}},
$$

where: $S_{x i}$ and $S_{y}$ are standard $x_{i}$ and $y$ deviations.

In addition to statistical tests, the assessment of the logic and justifiability of established relationships was conducted following the analysis of model applicability and testing under real-world conditions. 
Table 1. Postulated independent variables

\begin{tabular}{|c|c|}
\hline Notation & Demand measures \\
\hline$x_{1}$ & Total resident population \\
\hline$x_{2}$ & $\begin{array}{l}\text { Total land area according to the cadastral } \\
\text { register }\left[\mathrm{km}^{2}\right]\end{array}$ \\
\hline$x_{3}$ & $\begin{array}{l}\text { Population density [total resident population } \\
\text { per land area in housing] }\end{array}$ \\
\hline$x_{4}$ & Number of registered cars per 1000 inhabitants \\
\hline$x_{5}$ & GDP per head $[€]$ \\
\hline$x_{13}$ & $\begin{array}{l}\text { Proportion of the employed in-commuters } \\
\text { in the city [\%] }\end{array}$ \\
\hline \multirow[t]{2}{*}{$x_{14}$} & $\begin{array}{l}\text { Proportion of the out-commuting city } \\
\text { population [\%] }\end{array}$ \\
\hline & Supply measures \\
\hline$x_{6}$ & $\begin{array}{l}\text { Monthly public transport cost considering } \\
\text { the ratio of GDP per head }\end{array}$ \\
\hline$x_{7}$ & $\begin{array}{l}\text { Hourly parking fare considering the ratio } \\
\text { of GDP per head }\end{array}$ \\
\hline$x_{8}$ & Average journey time [min] \\
\hline$x_{9}$ & $\begin{array}{l}\text { Public transport network length per inhabitant } \\
\text { (km/capita) }\end{array}$ \\
\hline$x_{10}$ & $\begin{array}{l}\text { Public transport network density - public } \\
\text { transport network length } /\left[\mathrm{km} / \mathrm{km}^{2}\right]\end{array}$ \\
\hline$x_{11}$ & $\begin{array}{l}\text { Number of buses (or equivalent) operating } \\
\text { per } 1000 \text { inhabitants }\end{array}$ \\
\hline$x_{12}$ & $\begin{array}{l}\text { Number of buses (or equivalent) operating } \\
\text { per } 1 \mathrm{~km} \text { of the public transport network }\end{array}$ \\
\hline$x_{15}$ & $\begin{array}{l}\text { Number of public transport stops per } \mathrm{km}^{2} \\
\text { of the city area }\end{array}$ \\
\hline$x_{16}$ & $\begin{array}{l}\text { Number of public transport stops per } 1000 \\
\text { inhabitants }\end{array}$ \\
\hline$x_{17}$ & $\begin{array}{l}\text { Number of public transport stops per } 1 \mathrm{~km} \\
\text { of the public transport network }\end{array}$ \\
\hline$x_{18}$ & $\begin{array}{l}\text { Bicycle network length (dedicated cycle paths } \\
\text { and lanes) per } 1000 \text { inhabitants }\end{array}$ \\
\hline
\end{tabular}

Table 2. Postulated dependent variables

\begin{tabular}{cl}
\hline Notation & Variable description \\
\hline$y_{1}=P_{p t} / P_{p c}$ & $\begin{array}{l}\text { Probability ratio of public transport } \\
\text { to passenger cars }\end{array}$ \\
\hline$y_{2}=P_{p c}$ & Probability of using passenger cars \\
\hline$y_{3}=P_{p t}$ & Probability of using public transport \\
\hline$y_{4}=P_{w}$ & Probability of walking \\
\hline$y_{5}=P_{b y c}$ & Cycling probability \\
\hline$y_{6}=P_{m o t}$ & Probability of using motorcycles \\
\hline
\end{tabular}

In the last step, the final form of the model was selected and tested taking into account demand for travel in a city having 250000 inhabitants (Novi Sad, Serbia), comparing the modelled and empirical values of public transport to the probability ratios of using passenger cars. Data sourced from NOvi Sad TRansportation Model - NOSTRAM (Saobraćajna studija... 2009) were used as the test input data. The model was tested during the rush-hour (7 a.m. -8 a.m.) in the morning when the transport system problems are the most evident.

\section{Relevant Variables}

The analysis of the available city transport databases suggests that extremely similar transportation demand exists amongst the cities up to 500000 inhabitants. Thus, among 150 observed and selected cities (41 observations in 2001 and in 2004), $28^{1}$ had a possibility of collating all required data for model development and analysis. Through the correlation matrix analysis of the selected cities, 9 out of 18 independent variables were selected and based on their strongest effect on modal split. The chosen variables include the number of passenger cars/1000 inhabitants, GDP per inhabitant [€], monthly public transport cost considering the ratio of GDP per inhabitant, hourly parking fare considering the ratio of GDP per inhabitant, average journey duration [min], public transport network length [ $\mathrm{km} / 1000$ inhabitants], public transport network density $\left[\mathrm{km} / \mathrm{km}^{2}\right]$, the number of public transport busses (or the equivalent) per 1000 inhabitants [no. of vehicles/1000 inhabitants], proportion of out- commuters in the city [\%].

The selected variables exhibit the strongest effect on modal split between the passenger car and public transport. Consequently, the use of the probability ratio of public transport to passenger car was chosen as a dependent variable in the mathematical form of the modal split model.

The analysis of the correlation matrix yielded several conclusions:

- The strongest correlation can be observed between the probability ratio of public transport to using passenger cars usage on one side and the gross domestic product (GDP), public transport fare, parking fee, average journey duration and the number of busses per 1000 inhabitants on the other side of the equation. As expected, the probability of using public transport increases along with an increase in the parking fee and number of busses operating per 1000 inhabitants. In con-

\footnotetext{
${ }^{1}$ Tartu 2004, Koblenz 2004, Göttingen 2004, Linköping 2004, Darmstadt 2001, Darmstadt 2004, Braga 2004, Almere 2004, Odense 2004, Erfurt 2004, Freiburg im Breisgau 2001, Freiburg im Breisgau 2004, Magdeburg 2001, Magdeburg 2004, Kiel 2001, Kiel 2004, Kosice 2001, Kosice 2004, Augsburg 2001, Augsburg 2004, Mönchengladbach 2001, Mönchengladbach 2004, Malmö 2004, Wiesbaden 2001, Wiesbaden 2004, Karlsruhe 2001, Karlsruhe 2004, Aarhus 2004, Bonn 2004, Bielefeld 2001, Bielefeld 2004, Wuppertal 2004, Bochum 2001, Bochum 2004, Tallinn 2004, Bratislava 2004, Dresden 2004, Nürnberg 2001, Nürnberg 2004, Leipzig 2001, Leipzig 2004.
} 
trast, when the cost of public transport fare is higher (in relation to GDP), the use of passenger cars increases at the expense of public transport.

- Even though correlation values were less significant, reliable information was derived from the relationship between the number of registered cars per 1000 inhabitants, the percentage of outcommuters, public transport network density and length per inhabitant.

\section{Model Formulation}

Stepwise regression analysis was used in model development. The existence of strong correlations between individual independent variables allowed model development through several variable combinations (Table 3).

Table 3. Model development variants using stepwise regression analysis

\begin{tabular}{ll}
\hline & \multicolumn{1}{c}{ Variables } \\
\hline Variant I & $x_{4}, x_{5}, x_{6}, x_{7}, x_{8}, x_{9}, x_{10}, x_{11}, x_{14}$ \\
\hline Variant II & $x_{5}, x_{6}, x_{7}, x_{8}, x_{9}, x_{10}, x_{11}, x_{14}$ \\
\hline Variant III & $x_{5}, x_{6}, x_{7}, x_{9}, x_{10}, x_{11}, x_{14}$ \\
\hline Variant IV & $x_{6}, x_{7}, x_{9}, x_{10}, x_{11}, x_{14}$ \\
\hline
\end{tabular}

In each model variant, dependent variable $y$ is:

$$
y=\frac{P_{p t}}{P_{p c}},
$$

where: $P_{p t}$ is the probability ratio of using public transport and $P_{p c}$ is the probability of using passenger cars.

The variant of the first model includes all nine selected independent variables. With the exception of public transport network density $\left(x_{10}\right)$, these variables are included in the final model form due to their statistically significant partial correlations $(p<0.05)$ and beta coefficients. Based on analysis, the variables such as the number of busses in the network, the length of the public transport network and the participation of external commuters do not affect the independent variable in this model variant. The logical assessment of model validity was performed in the last two steps of the carried out analysis and suggested that in contrast to the nature of dependence an increased degree of motorization did not yield a greater probability of using passenger cars. Due to the positive correlation between the number of registered passenger cars and public transport to the probability ratio of passenger cars, Variant I model was rejected.

Stepwise regression analysis was repeated, whereby the number of registered passenger cars as the model input variable was excluded from the model (Variant II). In line with regression results obtained from the previous variant, the combination of independent variables such as average journey duration, parking fee, public transport fare and GDP per inhabitant have been included in the final form of the model and are characterized by significant partial correlation $(p<0.05)$ and significant beta coefficients. However, in contrast to the previous variant, this version of the model includes the number of busses and albeit with low influence on dependent variable. The same observation can be made when public transport network density is analyzed. Regression results and the correlation matrix analysis suggest that a high correlation between the number of busses per 1000 inhabitants and average journey duration resulted in the exclusion of the number of busses as the independent variable.

The significance of this variable as a measure of public transport quality and the effectiveness of transport policy lead to the exclusion of journey duration from the following model variant (Variant III).

The final model variant (Variant IV) further excluded GDP, given that parking fee and public transport fare have been already expressed in relation to GDP. Stepwise regression analysis yielded five new equations (Table 4).

Table 4. The key output results of the multiple stepwise regression analysis of Variant IV

\begin{tabular}{|c|c|c|c|c|}
\hline Steps & Regressions & $R$ & $R^{2}$ & $\sigma$ \\
\hline $\begin{array}{c}4.1(\text { Step I) } \\
t \\
p\end{array}$ & $\begin{aligned} y= & -0.433291+1.4601 x_{11} \\
& (-2.9967)(8.12436) \\
& (0.004992)(0.00000)\end{aligned}$ & 0.8084 & 0.6534 & 0.4543 \\
\hline $\begin{array}{c}4.2(\text { Step II }) \\
t \\
p\end{array}$ & $\begin{array}{l}y=-0.482+1.117 x_{11}+5452.411 x_{7} \\
\quad(-3.7842)(5.97817)(3.4095) \\
(0.0006)(0.0000)(0.001692)\end{array}$ & 0.86126 & 0.7418 & 0.3979 \\
\hline $\begin{array}{l}4.3 \text { (Step III) } \\
t \\
p\end{array}$ & $\begin{aligned} y= & 0.297+0.812 x_{11}+5808.711 x_{7}-449.377 x_{6} \\
& (1.3205)(4.6934)(4.32889)(-3.9387) \\
& (0.19575)(0.00005)(0.00013)(0.0004)\end{aligned}$ & 0.9079 & 0.8243 & 0.3331 \\
\hline $\begin{array}{c}4.4(\text { Step IV) } \\
\quad t \\
p\end{array}$ & $\begin{array}{l}y=0.23+0.815 x_{11}+4966.92 x_{7}-501.251 x_{6}-0.069 x_{10} \\
\quad(1.0485)(4.8458)(3.62912)(-4.4213)(1.8787) \\
(0.3022)(0.00003)(0.00098)(0.000106)(0.069426)\end{array}$ & 0.9175 & 0.8418 & 0.321 \\
\hline $\begin{array}{c}4.5(\text { Step V) } \\
t \\
p\end{array}$ & $\begin{array}{c}y=0.645+0.738 x_{11}+3503.897 x_{7}-477.64 x_{6}+0.086 x_{10}-0.019 x_{14} \\
(1.986)(4.3497)(2.2094)(-4.3002)(2.31379)(-1.6945) \\
(0.055931)(0.000137)(0.03467)(0.000158)(0.027478)(0.100196)\end{array}$ & 0.9411 & 0.8857 & 0.2772 \\
\hline
\end{tabular}

where: $t$ - the value of $t$-statistics; $p$ - sample probability that the corresponding parameter is equal to zero, i.e. not statistically significant; $R$ - correlation coefficient; $R^{2}$ - determination coefficient; $\sigma$ - standard error. 
The final equation of the target modal split model is produced incorporating influential variables:

$$
\begin{aligned}
y= & 0.645+0.738 x_{11}+3503.897 x_{7}- \\
& 477.64 x_{6}+0.086 x_{10}-0.019 x_{14} .
\end{aligned}
$$

After statistical and logical validity tests, the model developed in step 5 of Variant IV (model 4.5) was chosen as the final form of the Target modal split model (equation 4), the applicability of which was verified through testing the real example of travel demand in the city of Novi Sad, Serbia.

The second and probably even a more significant reason behind the selection of the final model is a set of independent model variables (with the exception of external commute participation) that are the key to transport policy development as well as to passenger car and public transport demand management. The final form of the chosen model includes variables as input parameters directly proportional to the probability ratio of using public transport to passenger cars: the number of busses operating per 1000 inhabitants, parking fee and public transport network density as well as variables having inversely proportional relationship, public transport fare and external commute participation.

As a consisting part of the strategy of integral traffic and parking planning, the application of the so called target modal split enables relations between certain modes of transport defined and based on objectives, i.e.

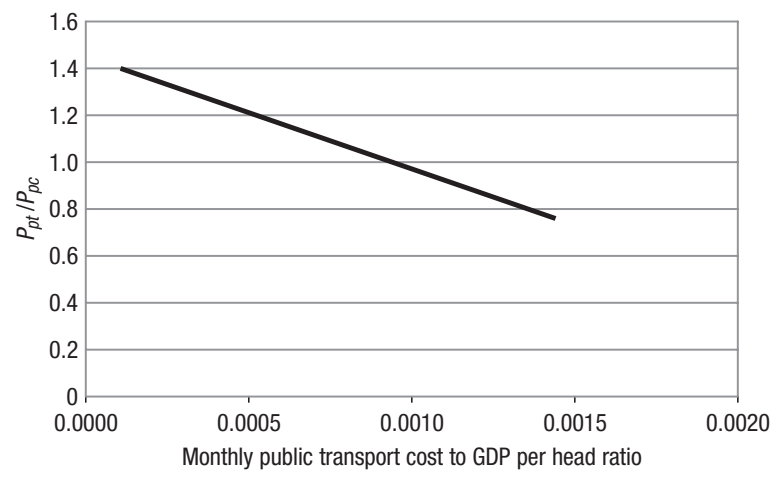

Fig. 1. The probability ratio of public transport to passenger car as a function of public transport fare

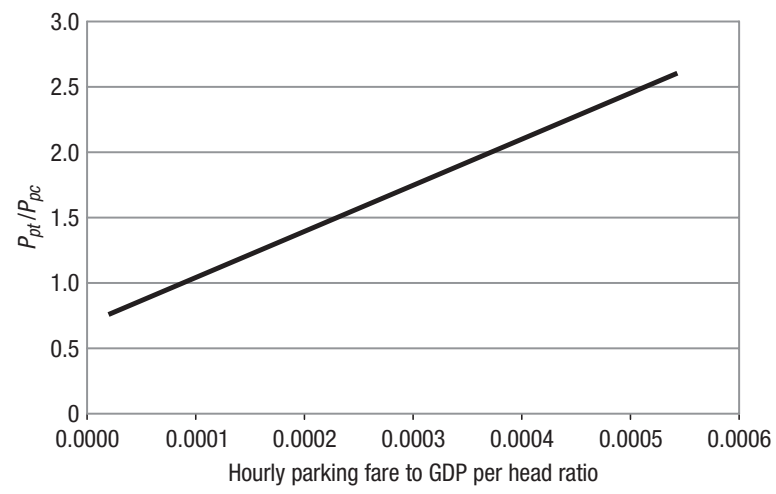

Fig. 2. The probability ratio of public transport to passenger cars as a function of a parking fee efforts to reduce the level of car use in towns, increase the attractiveness of public transport and create conditions for increasing pedestrian and bicycle traffic in towns.

By applying the target model, divergence curves were formed (Figs 1-4), which showed changes in the probability ratio of using public transport to passenger car as a function of changes in a single instrument (keeping the remaining variables as a constant).

Fig. 1 compares an increase in the results of transport fares considering a decreased probability of using public transport and passenger cars.

In cotnrast, as a consequence of higher parking charges (Fig. 2), public transport network density (Fig. 3) and the number of busses (Fig. 4) as quantities are directly proportional to the independent variable the probability of using public transport increases.

The presented diagrams of public transport showing passenger car probability ratio as a function of changes in a single transport policy instrument can also be viewed as one of the forms of modal split management. However, the significance of the target model developed as a multiple linear regression equation is evident in its potential for integrated transport system management in the urban area, the establishment of optimal public transport taking into account the ratio of using passenger cars and the combination of different parking control and public transport management measures.

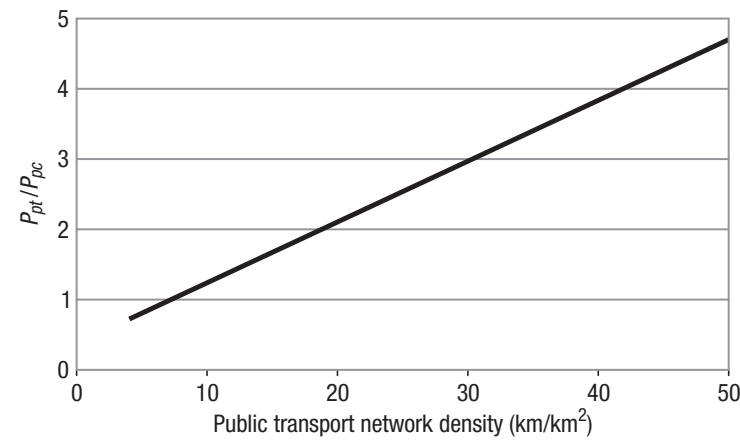

Fig. 3. The probability ratio of public transport to passenger cars as a function of network density

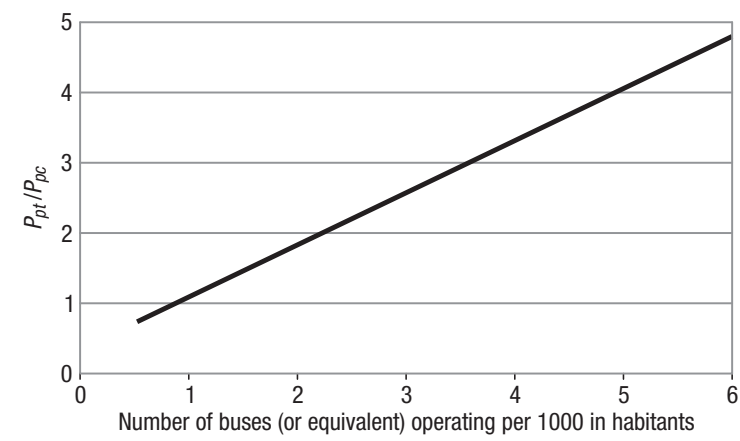

Fig. 4. The probability ratio of public transport to passenger cars as a function of the number of busses 


\section{Model Validation}

Model validity was tested in the city having 250000 inhabitants (Novi Sad, Serbia). Input data were recorded and stored in the city transport model database NOSTRAM (Saobraćajna studija... 2009).

According to empirical data, $45 \%$ of morning rushhour commuters are achieved by public transport, and $55 \%$ - using private passenger cars; thus, yielding the probability ratio of public transport to passenger cars makes 0.83 .

Monthly public transport fare and one hour parking fee are $15.84(€)$ and $0.2128(€)$ respectively.

Similarly, GDP for the tested city (Novi Sad) is $11030.7(€)$, public transport network density is $4.1(\mathrm{~km} /$ $\mathrm{km}^{2}$ ) and the number of busses (equivalent) $=0.53$ (vehicles/1000 inhabitants).

Based on the model, the probability ratio of using public transport to passenger car in the morning rushhour is 0.77 (i.e. public transport participation of $44 \%$ and $56 \%$ for passenger car journeys).

A comparison of the probability ratio of the modelled and empirical values of public transport to passenger cars in the total motorized journey modal split suggests that the model simulates a real situation with adequate reliability (Table 5).

The results of the model were validated according to the data obtained from three EU cities. The cities chosen for validation are Nurnberg (495302 inhabitants), Bratislava (425155 inhabitants) and Wuppertal (361077 inhabitants).

The factors presented in the below table (Table 6) are produced in order to form the final target modal split models for specific EU cities.

The presented data (Table 7) show the possibility of applying the target modal split model for different European cities.

Table 5. Modelled and surveyed values for Novi Sad

\begin{tabular}{lccc}
\hline $\begin{array}{c}\text { Dependent } \\
\text { variable }\end{array}$ & $y=P_{p t} / P_{p c}$ & PC part (\%) & PT part (\%) \\
\hline Model results & 0.77 & 56 & 44 \\
\hline Survey results & 0.83 & 55 & 45 \\
\hline
\end{tabular}

Table 6. Variable factors of the target modal split model for specific EU cities

\begin{tabular}{cccccc}
\hline \multicolumn{1}{c}{ City } & $x_{11}$ & $x_{7}\left(10^{-5}\right)$ & $x_{6}\left(10^{-3}\right)$ & $x_{10}$ & $x_{14}$ \\
\hline Nurnberg & 0.42 & 3.54 & 1.532 & 3.90 & 18.99 \\
\hline Bratislava & 2.29 & 8.73 & 0.031 & 1.69 & 3.13 \\
\hline Wuppertal & 0.81 & 5.76 & 1.978 & 3.80 & 23.89 \\
\hline
\end{tabular}

Table 7. Modelled and surveyed values for EU cities

\begin{tabular}{lccc}
\hline \multirow{2}{*}{ City } & \multicolumn{3}{c}{ Model / Survey values } \\
\cline { 2 - 4 } & $y=P_{p t} / P_{p c}$ & PC part. (\%) & PT part. (\%) \\
\hline Nurnberg & $0.50 / 0.58$ & $67 / 63$ & $33 / 37$ \\
\hline Bratislava & $2.71 / 2.70$ & $27 / 27$ & $73 / 73$ \\
\hline Wuppertal & $0.37 / 0.35$ & $73 / 74$ & $27 / 26$ \\
\hline
\end{tabular}

\section{Conclusions}

The obtained results show that the user's travel expenses, i.e. direct costs, including parking price and public transport fare most significantly influence a choice of transportation mode. Other authors (Souche 2010) have also identified travel expenses as the most significant; however, these are not the only factors that affect a choice between public transport and the use of private cars. A number of studies world-wide have shown that parking fees are dominant contributors to the overall travel costs, and are frequently cited as the most influential factors in deciding whether to use or not to use a passenger car (Hensher, King 2001; Kelly, Clinch 2006; Vračarević, Basarić 2007).

The existence of a significant correlation between supply measures for the transport system and the users' choice of transportation mode has enabled the development of the mathematical model in the final form of which, the model accepts input variables (transport policy instruments) that affect public transport to passenger car usage ratio, including parking fees and individual measures for public transport accessibility.

A comparison of the model and empirical values of public transport with using passenger cars within the total number of motorized trips in Novi Sad indicates that the applied model simulates actual conditions with sufficient reliability.

The significance of the target model and its potential implementation is primarily lies in the possibility of travelling demand management applying transport policy instruments as undependable variables, which is a feature of the final form of the model.

The limitation of the presented model stems from the limited applicability of individual transport policy instruments included as independent variables on the parking fee in particular. Increasing parking charges, if not accompanied by a corresponding increase in public transport capacity and improved service quality, cannot only be perceived as an unfair measure against car usage, but can also result in the decreased accessibility of certain urban areas and, consequently, reduction in the attractiveness and economic prosperity of the city. An increase in parking fees inevitably leads to a reduction of parking space utilization as well as to increased investment in the infrastructure of the public transport system.

The identified limitation implies further directions for improvements in the above presented target modal split model. Based on the demands of a specific city environment and the composition of the user group (demands in peak and off-peak periods), it is necessary to define the maximum parking fee as the upper limit that would enable sustainable modal split between public and private transport.

Further studies should also be directed towards exploring the impact of the implemented instruments on the ratio of motorized and non-motorized journeys as well as towards research into the possible inclusion of other instruments that may not be directly linked to transport policy such as technological innovations and land use policy instruments. 


\section{References}

Basarić, V. 2010. Model upravljanja raspodelom putovanja na vidove prevoza u funkciji održivog razvoja. Ph.D. Thesis, Faculty of Technical Sciences, University of Novi Sad. 202 p. (in Serbian).

European Urban Statistics for 258 Cities Across 27 European Countries. 2009. Urban Audit. Available from Internet: $<$ http://www.urbanaudit.org/help.aspx $>$.

Hensher, D. A.; King, J. 2001. Parking demand and responsiveness to supply, pricing and location in the Sydney central business district, Transportation Research Part A: Policy and Practice 35(3): 177-196. doi:10.1016/S0965-8564(99)00054-3

Jovanović, N. 1990. Planiranje saobraćaja. Monograph. Saobraćajni Fakultet, Univerzitet u Beogradu. 223 p. (in Serbian).

Jović, J. 1997. Application of neural networks to modal split modelling, Yugoslav Journal of Operations Research 7(1): $119-132$.

Jović, J., et al. 2008. Modeliranje transportnih potreba u funkciji zahteva mobilnosti $i$ energetske efikasnosti gradova. Ministry of Science and Technological Development Project. Saobraćajni Fakultet - Univerzitet u Beogradu (in Serbian).

Kelly, J. A.; Clinch, J. P. 2006. Influence of varied parking tariffs on parking occupancy levels by trip purpose, Transport Policy 13(6): 487-495. doi:10.1016/j.tranpol.2006.05.006

Litman, T. 2011. Win-Win Transportation Emission Reduction Strategies: Smart Transportation Strategies Can Reduce Pollution Emissions and Provide Other Important Economic, Social and Environmental Benefits. Victoria Transport Policy Institute. 18 p. Available from Internet: <http://www. vtpi.org/wwclimate.pdf $>$.

Ortúzar, J. D.; Willumsen, L. G. 2001. Modelling Transport. 3rd edition.Wiley. 514 p.

Saobraćajna studija grada Novog Sada sa dinamikom uređenja saobraćaja. 2009. NOSTRAM (NOvi Sad TRAnsportation Model). JP ‘Urbanizam' Zavod za urbanizam, Novi Sad, Serbia. 262 p. (in Serbian).

Souche, S. 2010. Measuring the structural determinants of urban travel demand, Transport Policy 17(3): 127-134. doi:10.1016/j.tranpol.2009.12.003

Vračarević, R.; Basarić, V. 2007. Uticaj naplate parkiranja na vidovnu raspodelu radnih putovanja, Tehnika - Saobraćaj 54(3): 21-26 (in Serbian). 